\title{
THE ROLE OF AIRBORNE EM METHODS FOR ENVIRONMENTAL APPLICATIONS IN DIFFERENT GEOLOGICAL TERRAINS
}

\author{
${ }^{1}$ British Geological Survey (BGS), Keyworth, Nottingham, NG12 5GG, UK \\ ${ }^{2}$ Geological Survey of Finland (GTK) \\ Beamish, D. and Mattsson, A., 2001. The role of airborne EM methods for \\ environmental applications in different geological terrains, EAGE 63nd Conference, \\ Amsterdam, Extended Abstracts, Paper IA-2. \\ Extended Abstract, June 2001. Session: The role of high resolution airborne surveys \\ in Environmental monitoring and sustainable development of resources.
}

\begin{abstract}
This paper reviews the increasing role of Airborne EM (AEM) methods for environmental purposes in a variety of geological contexts. The ability of AEM data to differentiate geological, cultural and environmental influences is considered using fixed-wing survey examples from Finland and the UK. The provision of AEM subsurface resistivity information constitutes a unique capability in relation to general remote-sensing information to which it is allied. To be fully exploited, the results of AEM surveys require both ground calibration and integration (e.g. through GIS techniques) with existing geological, hydrogeological and environmental databases.
\end{abstract}

\section{Introduction}

Increasing use is being made of airborne electromagnetic (AEM) surveying for assessing infrastructure, groundwater, land-use and environmental issues. In a number of these cases the resistivity information may be provided at a high lateral resolution scale and in the vicinity of populated areas. The ability of the data and processing methods to differentiate geological, cultural and environmental influences is then an important factor. Environmental influences on the near-surface resistivity distribution often arise due to enhanced pore fluid conductivities emanating from point and diffuse sources. The continuity of airborne information has the potential to identify preferential flow paths and, equally important, zones of natural attenuation. Clay mineralogies form important barriers (both natural and artificial) to fluid flow and thus geology and hydrogeology are natural partners in AEM environmental interpretation.

It should also be noted that environmental/land-use issues are not confined to anthropogenic sources. AEM data have also been used to assess the occurrence of fine-grained sulphidic sediments, which can be oxidised to harmful acid sulphate, soils (Puranen et al., 1999).

The AEM data discussed here were obtained with the GTK fixed wing system described in detail by Poikonen et al (1998). The coils are wing-tip mounted (separation of 17 or $21 \mathrm{~m}$, depending on aircraft) and are vertical coplanar. Coupling ratios at two frequencies (3.1 and $14.4 \mathrm{kHz}$ ) are recorded simultaneously at $4 \mathrm{~Hz}$. Sampling along the flight direction is typically between 10 and $15 \mathrm{~m}$. The system typically acquires EM data in addition to magnetic gradiometer (horizontal) and radiometric information. 
The system has been used for a number of specific environmental studies in Finland, the UK and eastern Germany. Within the geological terrains encountered (and associated near-surface resistivities sampled), coupling ratios extend from a few ppm to values in excess of 10,000. The geology encountered essentially defines a signal/noise issue for any particular environmental investigation. Near-surface geological complexity also defines an interpretation issue in that the separation of anthropogenic influences can be either hampered or aided. The most complex patterns observed in the UK data occur in areas of Quaternary cover containing, for example, glacial tills, gravels and clays. Geological mapping at 1:10K can provide highly detailed discrimination of tills and alluvium units, based on their source provenance. The small amount of AEM acquired in this context seems to reflect the complexity of these units. A greater degree of simplification appears in the absence of or only a minor contribution from, Quaternary cover as is demonstrated in Example 1.

\section{Example 1: conductive Jurassic clays}

An example from the largely Jurassic rock environment to the east of Nottingham serves to demonstrate the detectability of anthropogenic sources within a highly conductive environment. A 4 x $1.5 \mathrm{~km}$ area was flown with the GTK system using $50 \mathrm{~m}$, E-W flight lines at a nominal flight altitude of $40 \mathrm{~m}$. Figure 1 shows a map (1:50K) of the Langar survey area. Superimposed on the map are selected zones of the resistivity distribution obtained by formal $1 \mathrm{D}$ inversion of the lower frequency ( $3.1 \mathrm{kHz}$ ) coupling ratios. The data comprise over $70001 \mathrm{D}$ models and some of the models have been rejected on the basis of multidimensional influences (Beamish, 2001).

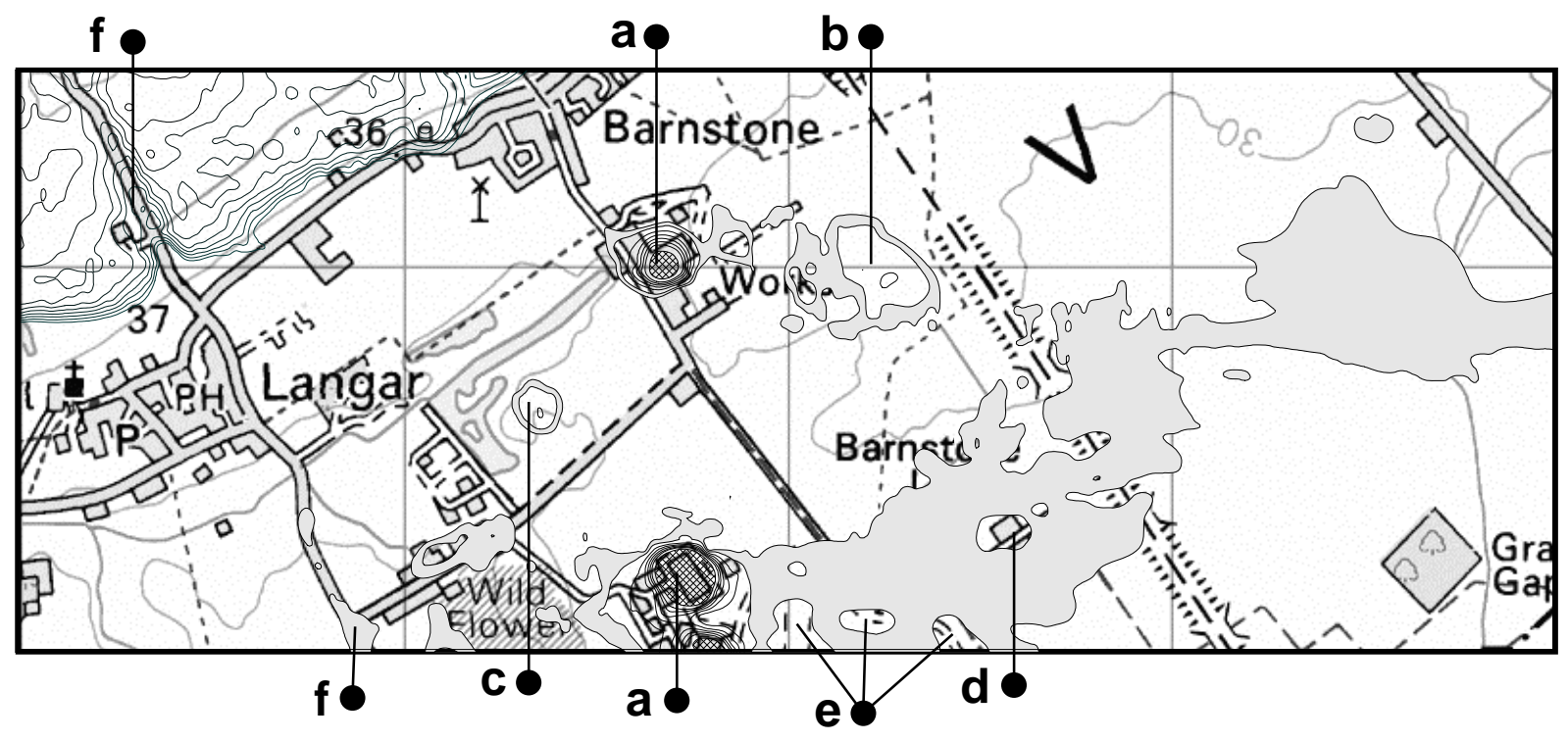

Figure 1

Location map of the Langar example survey area $(4 \times 1.5 \mathrm{~km})$. Selected contours of the conductivity distribution inferred from inversion of the lower frequency data. NW corner 30-75 mS/m contours, increasing to SE. Gray contoured region is 250 to $300 \mathrm{mS} / \mathrm{m}$. Other contours are 300 to $1000 \mathrm{mS} / \mathrm{m}$, interval of 100 with conductivities $>1000 \mathrm{mS} / \mathrm{m}$ hatched. Labels (a to f) are described in the text. (c) Crown copyright. All rights reserved.

Three broad conductivity 'levels' differentiate the main geological units across the area. In the NW, conductivities between 30 and $75 \mathrm{mS} / \mathrm{m}$ define the Mercia Mudstone group. These conductivities, contoured in Figure 1, show a strong gradient to the SE, which marks the contact with a Lower Lias limestone unit. Further to the SE is an extensive zone of Lower Lias clays. The most conductive zone of this formation (appearing as an unmapped 'trough') has conductivities in the range 250 to $300 \mathrm{mS} / \mathrm{m}$ and is shown infilled in gray. The environmental interpretation of these data concerns the reliable detection of

EAGE 63rd Conference \& Technical Exhibition - Amsterdam, The Netherlands, 11 - 15 June 2001 
zones of enhanced conductivity and their discrimination from possible geological contributions. Contours of conductivity values in the range 300 to $1000 \mathrm{mS} / \mathrm{m}$ are shown with values in excess of $1000 \mathrm{mS} / \mathrm{m}$ being hatched. All the zones defined by these contours appear to identify well-contained isolated zones of enhanced conductivities due to individual anthropogenic sources. The two most conductive zones, labelled (a) are associated with large industrial works (e.g. cement manufacture). The gray zone (b) surrounds a more conductive zone associated with a number of cells within an active landfill. The small zone (c) precisely outlines a former closed landfill. Within the conductive clay trough, conductive zones (> $300 \mathrm{mS} / \mathrm{m}$ ) appear due to a farm, labelled (d), and aerodrome runways, labelled (e). A persistent quasilinear zone tracks one of the main roads through the area and is labelled (f) in Figure 1.

\section{Example 2: sandstone aquifer}

Investigations into environmental effects above the Permo-Triassic sandstone aquifer were conducted in northern Nottinghamshire. Here the geology is highly uniform (Sherwood Sandstone) and representative 'background' conductivities could be established in zones away from known/potential sources. A pitfall in this procedure when applied to well established areas of population is the extent of near-surface reworking and dumping. Only recently has 1:10K geological mapping attempted to identify areas of made and remade ground (the new geology). Anomalies were, in fact, detected in the AEM data prior to their subsequent identification from historical records. The procedure has established that within the survey area $(13 \times 9 \mathrm{~km})$ normal conductivities (largely within the unsaturated zone at depths of $<40 \mathrm{~m}$ ) should not exceed about $15 \mathrm{mS} / \mathrm{m}$ at the survey frequencies used. By mapping zones with conductivities in excess of, say, $30 \mathrm{mS} / \mathrm{m}$ likely anthropogenic sources can be 'safely' identified.

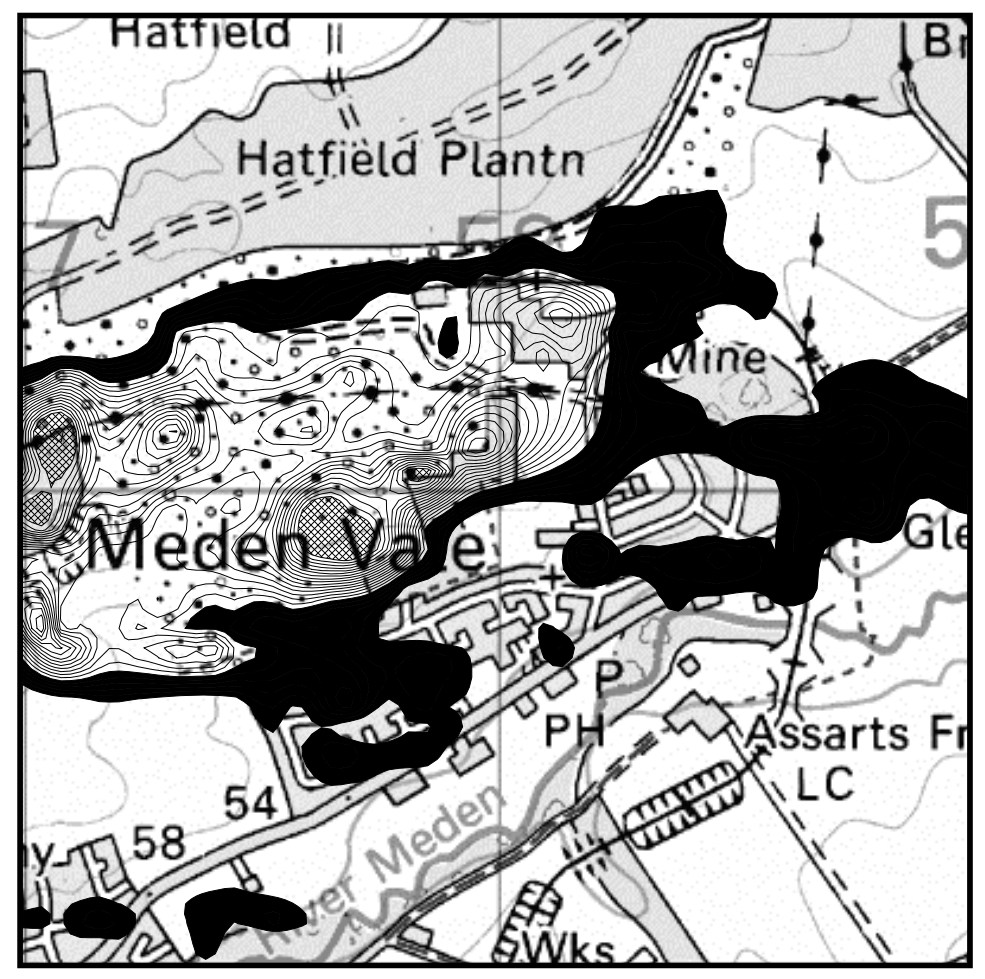

Figure 2

Location map of Welbeck colliery $(2 \times 2 \mathrm{~km})$. Selected contours of the conductivity distribution inferred from inversion of the lower frequency data. 50 to $100 \mathrm{mS} / \mathrm{m}$ in black. 100 to $1000 \mathrm{mS} / \mathrm{m}$ contoured using an interval of 100 . Conductivities > $1000 \mathrm{mS} / \mathrm{m}$ hatched. (C) Crown copyright. All rights reserved.

The area surveyed is part of the Nottinghamshire coalfield and contains a series of former and working collieries. A major result of the AEM survey was the regional significance of the enhanced conductivities associated with the collieries and spoil zones. Although landfill, agricultural and other anomalies could be 
identified, the volume, extent and high conductivities associated with these zones appear to be highly significant. The soil classification indicates deep permeable coarse textured soils, which readily transmit a wide range of pollutants because of their rapid drainage and low attenuation potential.

An example of the results obtained across the working Welbeck colliery is shown in Figure 2. The lower frequency 1D inversion results are shown, selectively contoured, on a base map (1:50K). The main spoil zone (stippled) occurs in the central, western area. Superimposed on the map are the conductivity contours which exceed $50 \mathrm{mS} / \mathrm{m}$. The most conductive zones (250 to $300 \mathrm{mS} / \mathrm{m}$ ), which occur within the spoil area of the mine, are hatched. The zone having conductivities between 50 and $100 \mathrm{mS} / \mathrm{m}$ is shown in black. This zone appears to represent possible subsurface flowpaths from the source region of enhanced conductivity fluids. As implied in the Figure, such possible flowpaths can be traced over distances exceeding $1 \mathrm{~km}$.

One of the main concerns of the study was aquifer vulnerability. Here, vulnerability maps are prepared at a scale of $1: 100 \mathrm{~K}$. The maps involve an acknowledged compromise between the representation of natural complexity and ease of interpretation. The maps also acknowledge that where the soil and/or underlying formations has been disturbed or removed, there will be a need to determine groundwater vulnerability using site-specific data. It appears from our results that the site-specific information can be provided by AEM and thereby assist with the limitations of existing protocols.

\section{Summary}

In developed areas, AEM studies may provide environmental diagnostics in the context of a large amount of existing information on land-use quality. A number of land-use and environmental studies are, in addition, allied to the use of remotely-sensed information (e.g. satellite and high-level airborne in the optical and thermal bands). Although extremely useful, particularly with the enhanced resolutions of modern systems, they can understood as part of a continuum of electromagnetic remote sensing. In these terms, such techniques essentially 'scratch the surface' for diagnostic information. AEM, in the context of remote sensing, constitutes low-level surveying. Three of the key roles of AEM which uniquely define its value in remote sensing for environmental applications are:

- Lifting the lid. AEM provides subsurface information of environmental diagnostics on a scale that extends to tens of meters in depth.

- Fluid geochemistry. AEM provides bulk resistivity information, which exhibits a high degree of sensitivity to pore water geochemistry.

- Site-investigation scale. AEM has the potential to provide regional and local scales of information.

Although used for over a decade for environmental assessments in the hard-rock environment of Finland (e.g. Jokinen and Lanne, 1996), the initial AEM data sets obtained in 'average' UK geology have proved revealing. Work to exploit their integrated potential in relation to existing geological, hydrogeological and environmental data sets is in progress.

\section{References}

Beamish, D., 2001. A study of conventional and formal inversion methods applied to high resolution AEM data. Geophys. J. Int., submitted.

Jokinen, T. and Lanne, E., 1996. Airborne geophysics in mapping contaminant plumes from landfills. SAGEEP Extended Abstracts, Keystone, Colorado, pp 981-995. 
Poikonen, A., Sulkanen, K, Oksama, M. and Suppala, I., 1998. Novel dual frequency fixed wing airborne EM system of Geological Survey of Finland (GTK). Exploration Geophysics, 29 (1-2), 46-51.

Puranen, R., Säävuori, H., Sahala, L., Suppala, I., Mäkilä, M. \& Lerssi, J., 1999. Airborne electromagnetic mapping of surficial deposits in Finland, First Break, May 1999, 145-154. 